\title{
Influence of no-till practices on the organic matter chemical composition of Protocalcic, Endocalcic and Pantocalcic Cherno- zems
} \author{
kita Ermolaevi', Victor Dridiger², Boris Ilyin ${ }^{3}$, Vladimir Lazarev³, Victor Belobrov ${ }^{1}$

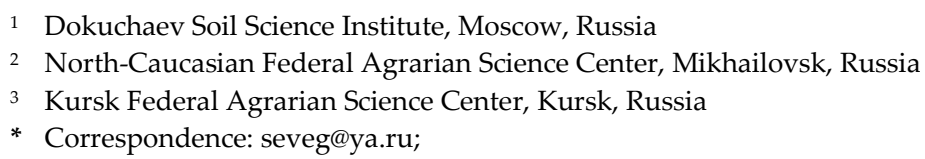

Vladimir Kholodov ${ }^{1}$, Yulian Farkhodov ${ }^{1}$, Nadezhda Yaroslavtseva ${ }^{1}$, Svyatoslav Maximovich ${ }^{1, *}$, Sergei Yudin ${ }^{1}$, Ni-

Abstract: Reducing the amount of precipitation in summer in the Chernozems area alters soil organic matter (SOM). To compensate for the lack of moisture, farmers are introducing new agricultural technologies such as no-till cultivation. In turn, no-till practices influence the composition of SOM. We examined the impacts of the rise of aridity and no-till technology on the chemical composition of bioavailable and recalcitrant pools of OM. The properties of SOM were assessed using double-shot pyrolysis with gas chromatography/mass spectrometry (GC/MS). The thermolabile substances that are volatilised in the first stage of pyrolysis $\left(300^{\circ} \mathrm{C}\right)$ are considered the bioavailable pool. Accordingly, substances are obtained in the second pyrolysis stage $\left(500^{\circ} \mathrm{C}\right)$ were attributed to the recalcitrant pool. Identified in both steps of pyrolysis, products were assigned to different chemical groups (lignin-derivative, polysaccharide-fragments, indoles, etc.) and relative abundances were calculated. In work for the separation of substances, a polar column was used for chromatography of the thermolabile fraction. With an increase in aridity in Chernozems, the content in the bioavailable pool of polysaccharide fragments decreased and the proportion of indoles increased. In the recalcitrant pool, the abundance of six-membered rings with nitrogen and aromatic compounds decreases at the same time the contents of unsubstituted and $\mathrm{O}$-substituted acyclic compounds as well as pyridine increases. The influence of the NT was more noticeable in the recalcitrant OM. The NT practice promotes biological activity and to rich in nitrogen compounds the bioavailable OM; this process contributes to the accumulation of carbon in the recalcitrant OM.

Keywords: Double-shot-pyrolysis-GC/MS; Chernozems; No-till; soil organic matter; (List three to ten pertinent keywords specific to the article yet reasonably common within the subject discipline.)

\section{Introduction}

Soil organic matter is a key component of the pedosphere and in many respects determines soil fertility, buffer capacity, erosion resistance and other properties as well as the global carbon cycle [1]. The carbon accumulation in soils is frequently associated with processes of restoration after a change in land use. Changing to no-till practices in agriculture, as an alternative to conventional tillage, causes an accumulation of organic carbon in the soil, at least in soil with a moisture deficit during the growing season $[2,3,4]$. In particular, the soils of humid continental climates with hot summers, such as Chernozems, demonstrated significant increases in organic carbon content after the introduction of no-till practices [5]. However, it is still not clear how the molecular composition and properties of organic matter $(\mathrm{OM})$ change during the transition from continuous tillage agriculture to no-till practice. In addition, since the effect of a no-till system is associated with lack of water it is actually a study of the quality of substance depending on 
the aridity. Thus, the goal of this work was to evaluate changes in the structure of the $\mathrm{OM}$ of Chernozems depending on aridity and the use of no-till technology.

The thermal stability of any material is strongly related to the activation energy needed for its pyrolysis or combustion. The recalcitrance of SOM may be considered as a high barrier of activation energy to the enzymes involved in the depolymerisation and decomposition of organic molecules [6]. The methods of thermal analysis allow the separation of SOM by thermal fractions. The temperature threshold of $300-400^{\circ} \mathrm{C}$ is interpreted as a measure of SOM lability or stability against decomposition $[7,8,9]$. This approach supports the estimation of mean residence times of thermal fractions. The study of carbon isotopic composition of thermal fractions of soils subjected to C3-C4 vegetation demonstrated that the increase of SOM stability with rising temperature was not gradual. Whereas the most stabile thermal fraction $\left(t>480^{\circ} \mathrm{C}\right.$ ) had a MRT of 168 years, the MRTs other fractions were 10.5-15.4 years [10]. The thermolabile (TL) fraction was related to the susceptibility of carbon to decomposition assessed through laboratory incubation [11]. Double-shot pyrolysis allows the sequential examination of the products released by thermal desorption (TL) and by thermal cracking (thermostable fraction: TS) from the same sample [12]. Analysis by pyrolysis indicated that the thermolabile fraction was related to the bioavailability of $C$ [13]. This temperature threshold is interpreted as a measure of SOM lability or stability against decomposition $[7,8,9]$. In addition, the application of fresh organic residuals to the soil increased the thermolabile fraction more than the thermostable fraction [14]. Our data obtained for Chernozems of long-term experiments also confirmed that the TL fraction is represented by a bioavailable OM, while the TS is more recalcitrant. The chromatograms of TL OM in soils with very high bioavailable OM contents (virgin Chernozem in an annually mown steppe) had more diversity and intensity of peaks in comparison with tillage Chernozems and especially with the treatment "permanently tilled fallow since 1964" [15].

\section{Materials and Methods}

In this work, the composition of organic matter was explored by double-short pyrolysis of soils with different aridities: Protocalcic, Endocalcic and Pantocalcic Chernozems of long-term experiments under conventional tillage or no-till practice.Materials and methods2.1 Study sites and soils

In this study, the effects of aridity, climate and tillage system on OM in the East European Plain Chernozems were presented for three experimental sites located on carbonate loesses with different depths of calcium in the soil profile. Accordingly, the aridity of Chernozems increases with a decrease in the depth of calcium in the soil. Protocalcic Chernozems contain calcium of secondary carbonates on depths $>100 \mathrm{~cm}$, Endocalcic Chernozems contain calcium of secondary carbonates on depths $>50 \mathrm{~cm}$ and Pantocalcic Chernozems contain carbonates from the soil surface [16]. Samples were obtained of continuous tillage (CT) and no-till (NT) systems. Sampling was carried out in 2017. The notill system was used during years 4, 5 and 12 on Protocalcic Endocalcic and Pantocalcic Chernozems respectively.

The Protocalcic Chernozems were sampled at the long-term field experiment of the Kursk Federal Agrarian Science Centre (Cheremushki, Kursk District, Russia, 51 ${ }^{\circ} 37^{\prime} 46^{\prime \prime}$ $\mathrm{N}, 36^{\circ} 15^{\prime} 40^{\prime \prime}$ E). The experiment had an area of 2.4 ha in plots of $60 \times 100 \mathrm{~m}$ and involved a four-field crop rotation scheme (winter wheat, corn, barley and pea) for both NT and CT systems [5](Kholodov et al., 2021).

The Endocalcic Chernozems were sampled at the experimental field station with the North-Caucasian Federal Agrarian Science Centre (Mikhailovsk, Stavropol region; $45^{\circ} 07^{\prime} 34.9^{\prime \prime} \mathrm{N}, 42^{\circ} 03^{\prime} 24.0^{\prime \prime} \mathrm{E}$ ). The long-term field experiment there covers an area of 2 ha with plots of $50 \times 18 \mathrm{~m}$ in a rotation scheme involving soybean, winter wheat, sunflower and corn [5]. The Protocalcic Chernozems were sampled in the commercial fields of the

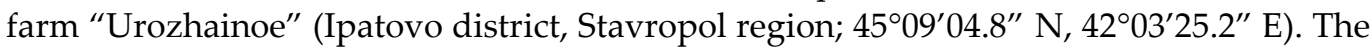


NT system was successfully used there for 12 years [5]. The samples of the soil of the adjacent field with intensive conventional tillage (CT) were used as a control.

The sampling was performed on the testing site at a radius of $5 \mathrm{~m}$. Five subsamples $(5-7 \mathrm{~kg})$ were taken: four at the edges and one in the centre of the site at a $0-15 \mathrm{~cm}$ depth. Each subsample was transformed to an average sample $(5 \mathrm{~g})$ by multiple random mixed parts of the subsample. Average samples have been used for double-shot pyrolysis Thus, each variant was analyses in five replicates.2.2 Double-shot pyrolysis

Double-shot pyrolysis GC/MS was performed using an EGA/PY3030D double-shot pyrolyser (Frontier Lab Ltd., Fukushima, Japan) attached to GCMS-QP2010Ultra (Shimadzu, Japan) GC/MS. Soil samples of about $10 \mathrm{mg}$ were loaded into the cup. The sample cap was placed in the furnace preheated at $100{ }^{\circ} \mathrm{C}$. For the isolation thermo-labile organic matter (TL OM) the temperature was raised to $300{ }^{\circ} \mathrm{C}$ at a rate of $20^{\circ} \mathrm{C}$ per min and held for $8 \mathrm{~min}$ (first pyrolysis step). The evolved products are directly injected into the GC/MS. Then for the isolation thermo-stable organic matter (TS OM), the sample cap was placed under $500^{\circ} \mathrm{C}$ for $1 \mathrm{~min}$ (second pyrolysis step) and evolved products passed to GC/MS.

The GC was equipped with a polarity column of crosslinked polyethylene glycol filled GsBP-Inowax-MS (30 $\mathrm{m} \times 0.25 \mathrm{~mm} \times 0.25 \mu \mathrm{m}$ film thickness). The preliminary experiments (see S1) demonstrated more effective separation of TL OM products in comparing widely used non-polar columns with $95 \%$ dimethyl $/ 5 \%$ diphenyl polysiloxane in stationary phase (type of GsBP-5ms). The initial temperature of the GC oven was $50{ }^{\circ} \mathrm{C}$; the column heating was to $240{ }^{\circ} \mathrm{C}$ at a rate of $10{ }^{\circ} \mathrm{C}$ per min and held at $240{ }^{\circ} \mathrm{C}$ for $1 \mathrm{~min}$. The mass detector scanned molecular weights of 50 to $600 \mathrm{~m} / \mathrm{z}$ with a $70 \mathrm{eV}$ ionising energy of electron impact. Compound identification was achieved via comparison with NIST 11 library, monitoring of characteristic ions and data from the literature $[12,17,18,19]$. Data analysis of first step pyrolisis was estimated for peak areas of the characteristic ions. Their relative amounts (\%) were calculated with respect to this sum. Composition of TS OM was assessed similarly only instead of individual ion current used peaks of total ion current (TIC). The TS OM compounds were divided based on derivatives of plant residuals or chemical classes (acyclic alkanes, aromatics, N-containing compounds and polysaccharide fragments, among others) if the individual substance was present in a sufficiently large amount, it was not included in classes and was instead considered separately (toluene, phenol, pyridine and benzene).

Because of both pyrolysis steps, data matrices contain a compositional data (sum of each row $=100 \%$ ), each matrix was prepared for principal components analysis (PCA) by the centered logratio transformation to the working matrix $\operatorname{clr}(x)[20,21,22]$ according to the equation: $\operatorname{lr}(\mathrm{x})=[\lg \{\mathrm{x} 1 / \mathrm{g}(\mathrm{x})\}, \ldots . \lg \{\mathrm{xi} / \mathrm{g}(\mathrm{x})\}]$, where $\mathrm{x}$ is the initial data and $\mathrm{g}(\mathrm{x})$ their geometric mean.

\section{Results}

\subsection{Thermolabile Organic Matter}

A complete list of identified substances, their characteristic ions and retention times are presented in the supplementary materials (Table S1). In the composition for the pyrolisates of TL OM, pyrrole and isomers of methylpyrroles were combined in the group "Pyrroles", and isomers of methylphenol were grouped in "Me-phenols" (Table 1). The indoles content was estimated on a broad selective ion peak for m/z 117 (Fig. S1).

Table 1. Relative abundance (averages, \%) of individual substances and chemical groups for the pyrolisates of thermolabile organic matter pyrolisates of Chernozems under different land management types*

$\begin{array}{llll}\text { Chernozems } & \text { Protocalcic } & \text { Endocalcic }\end{array}$




\begin{tabular}{ccccccc} 
Land management & NT & CT & NT & CT & NT & CT \\
\hline Pyridine & 2 & 2 & 2 & 9 & 2 & 2 \\
2-Cyclopenten-1-one & 5 & 4 & 1 & 4 & 1 & 1 \\
3-Furaldehyde & 10 & 12 & 11 & 6 & 5 & 4 \\
Furfural & 56 & 62 & 43 & 24 & 12 & 11 \\
Pyrroles & 2 & 3 & 6 & 18 & 8 & 7 \\
5-Methyl-2-furancarboxaldehyde & 6 & 6 & 2 & 4 & 1 & 1 \\
Indoles & 12 & 5 & 26 & 22 & 61 & 63 \\
Phenol & 2 & 3 & 5 & 10 & 7 & 7 \\
1H-Pyrrole-2-carboxaldehyde & 3 & 3 & 1 & 1 & 1 & 1 \\
Me-phenols & 1 & 1 & 1 & 3 & 2 & 2 \\
\hline
\end{tabular}

*Standard deviations are shown in Table S2

In general, the pyrolisates of TL OM composition demonstrated substantial dependence on Ca content in the soils (aridity). In the row of increasing of Chernozems aridity Protocalcic $<$ Endocalcic $<$ Pantocalcic abundance of furan derivatives decreases (especially furfural) and content of indoles increases. The influence of NT on TL OM is most pronounced in Endocalcic Chernozem. In addition, there is a distinction between NT and $\mathrm{CT}$ in Protocalcic Chernozems. In the case of Pantocalcic Chernozems, there were no significant differences between average values of relative abundance of compounds from NT and CT treatments.

Application NT practice causes substantial increases in the share some pytolisates such as indoles in Protocalcic Chernozems and furfural and 3-furaldehyde in Endocalcic Chernozems. Moreover, the abundance of pyrroles, 2-cyclopenten-1-one, 5-methyl-2furancarboxaldehyde and phenol decreases under NT in the composition for the pyrolizstes of TL OM of Endocalcic Chernozems. Figure 1 shows the distribution in principal components (PC) space of Chernozems depending on their TL OM composition. The PC1 and PC2 describe 76\% variation of TL OM of the Chernozems. The main compounds that determine differences were established by PCA eigenvectors (Table S3). These substances are shown in Figure 1 by an arrow.

Axis PC1 mainly divides Chernozems by their aridity, and in the case of the Endocalcic variant, additionally separates NT and CT practices. At increasing negative values of PC1 (less aridity), the content of some pyrolysates of polysaccharides (furanes) increases; at increasing positive values of PC1 (more aridity), the share of phenols and pyrroles, which are derived from lignin and proteinaceous material respectively, increases. The accumulation of pyrolysates of polysaccharides (furanes) and a decrease in the proportion of N-substances are characteristic of less decomposed OM [23]. In this way with increasing aridity, Chernozems increase the degree of decomposition of their TL OM. A shift along the PC1 axis between the NT and CT treatments of Endocalcic Chernozems explained a more favourable water regime under NT. The NT technology facilitates the retention of moisture in the soil.

Axis PC2 more reflects the shift in the TL OM due to the use of NT or CT technology in Endocalcic Chernozems. There is a tendency to change content of some pyrolysates proteinaceous material for a rise in the share indoles and reducing pyridines under NT.

Protocalcic and Pantocalcic Chernozems TL OM demonstrate a weak response to of agro-technology. In the case of the Protocalcic subtype, the lack of divergence between the NT and CT for TL OM can be explained by significantly large quantities of organic 
carbon 3.1-3.5\% in comparison with other Chernozems 2.1-3.2\% [5]. The greater the content of the organic matter, the slower the TL fraction reacts to the introduction of the NT. Likely, four years of using NT is not enough time for notable differences to appear.

In contrast, Pantocalcic Chernozems were cultivated under NT for 12 years [5], but they contained 2.1-2.6 \% of organic carbon and high Ca contents from the surface of the soil. We suppose the presence of the $\mathrm{Ca}$ in the Chernozems reduces the transformation ability of TL OM under land management. This could explain the case of total domination of $\mathrm{Ca}$ in Chernozems; all groups of TL OM are bound with Ca. This, on the one hand, decreases the diversity of OM forms, and on the other hand, increases their sustainability.

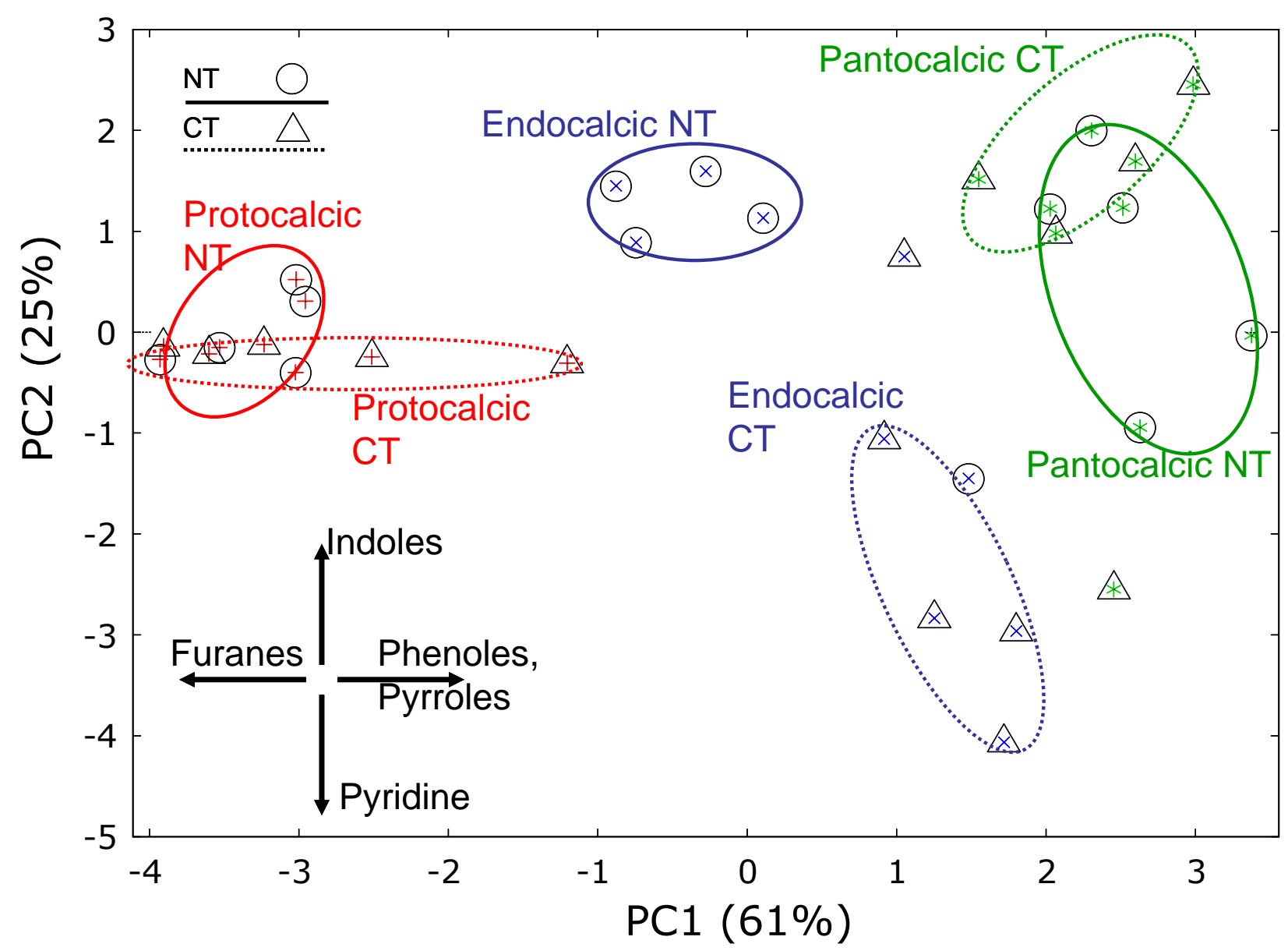

Fig. 1. Distribution of Chernozems with different aridity (Proto, Endo and Pantocalcic) and agrotechnology (NT or CT) in PC spacebased TL OM composition.

\subsection{Thermostable Organic Matter}

The complete list of identified the pyrolisates of TS OM is present in the supplementary materials (Table S4). The relative abundances of compounds were calculated by their TIC peaks. The compounds were combined in classes according to their origin or chemical structure (Table 3, Table S4).

Table 3. Relative abundance (averages, \%) of compound groups and individual pyrolisates* of thermostable organic matter of Chernozems under different land management types**

\begin{tabular}{ccccccc}
\hline Chernozems & \multicolumn{2}{c}{ Protocalcic } & \multicolumn{2}{c}{ Endocalcic } & \multicolumn{2}{c}{ Pantocalcic } \\
\hline Land management & NT & CT & NT & CT & NT & CT \\
\hline
\end{tabular}




\begin{tabular}{|c|c|c|c|c|c|c|}
\hline \multicolumn{7}{|c|}{$\mathrm{N}$-contain substances } \\
\hline N6 & 5 & 4 & 4 & 3 & 4 & 3 \\
\hline N5 & 13 & 13 & 13 & 12 & 12 & 12 \\
\hline $\mathrm{N}$ & 10 & 10 & 9 & 10 & 10 & 10 \\
\hline $\operatorname{Pr}$ & 6 & 6 & 7 & 8 & 8 & 6 \\
\hline \multicolumn{7}{|c|}{ Polysaccharide fragments } \\
\hline PscF & 17 & 19 & 18 & 19 & 15 & 15 \\
\hline Pscyclo & 8 & 8 & 8 & 6 & 7 & 8 \\
\hline Psc & 4 & 4 & 3 & 3 & 3 & 3 \\
\hline \multicolumn{7}{|c|}{ Acyclic alkanes } \\
\hline Alk & 11 & 10 & 11 & 13 & 14 & 13 \\
\hline AlkO & 3 & 3 & 3 & 3 & 4 & 3 \\
\hline \multicolumn{7}{|c|}{ Aromatic compounds } \\
\hline $\mathrm{Ar}$ & 8 & 7 & 6 & 5 & 4 & 6 \\
\hline $\mathrm{Bz}$ & 3 & 3 & 3 & 3 & 3 & 3 \\
\hline $\mathrm{Ph}$ & 5 & 5 & 6 & 5 & 5 & 6 \\
\hline $\mathrm{T}$ & 4 & 4 & 4 & 4 & 5 & 4 \\
\hline
\end{tabular}

*Classes: N6 pyridines heterocycles, N5 pyrroles heterocycles, N other nitrogen contain compounds, PscF polysaccharide fragments with furanes, Pscyclo - cycloalkanes probably polysaccharide fragments, Psc other polysaccharide fragments, Alk Acyclic alkanes, AlkO Acyclic substituted alkanes, Ar aromatic contain compounds. Individual compounds: $\mathrm{Bz}$ benzene, $\mathrm{Ph}$ phenol, $\mathrm{T}$ toluene, $\mathrm{Pr}$ pyridine.

**Standard deviations are shown in Table S5

In general, in the TS OM of Chernozems, N-compounds and polysaccharide fragments prevail. At the same time, among derivatives of carbohydrates, substances with furan rings dominate. $\mathrm{N}$-compounds are predominantly represented by pyrroles. An analysed average value of relative abundance of TS OM compounds (Table 3) does not establish clean links nor aridity or land management of Chernozems. From the PCA, the wellseparated variants depended on soil subtype and agronomy practices in PC1-PC2 space (Fig. 2). 


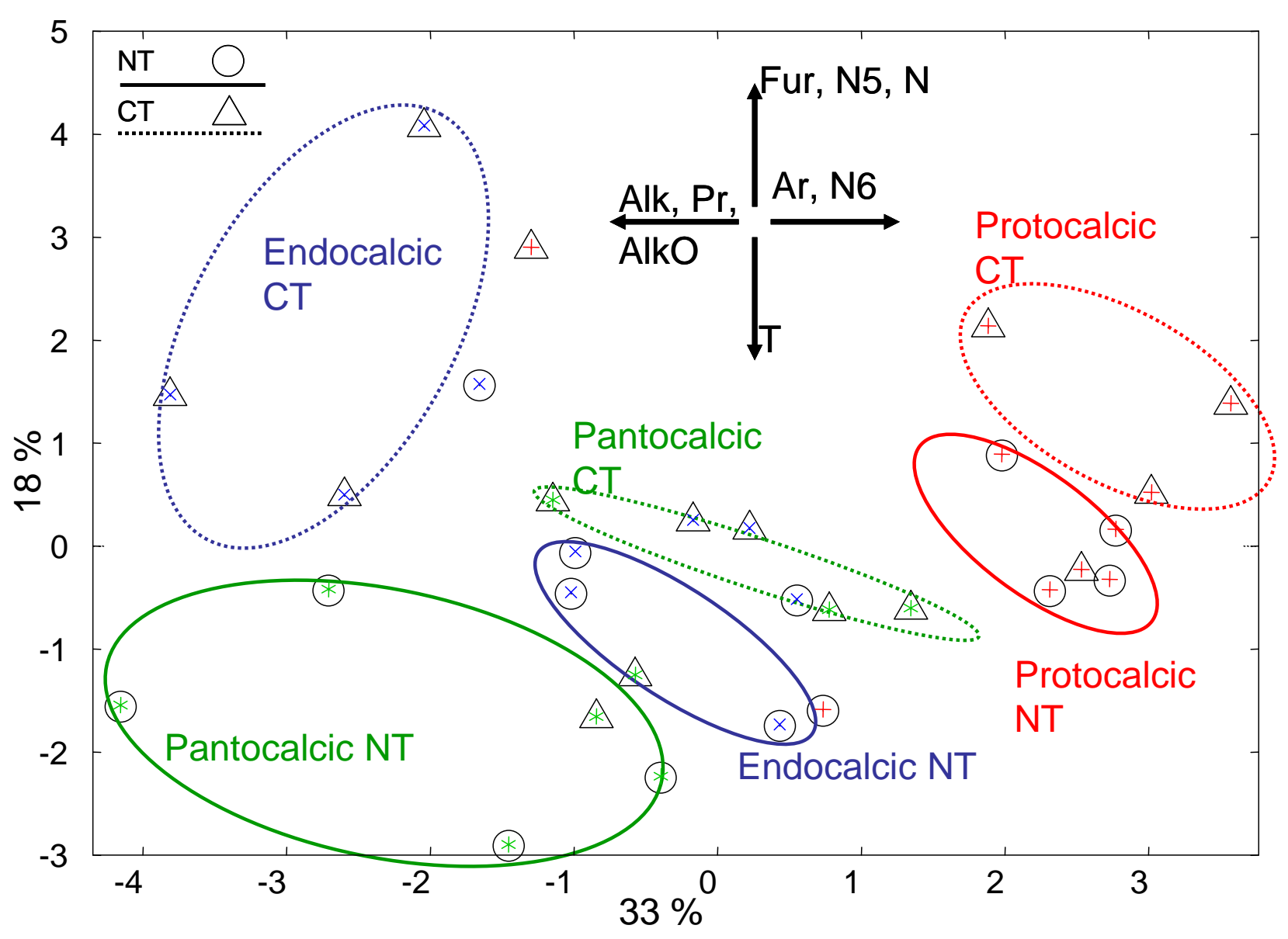

Fig. 2. A distribution of Chernozems with different aridity (Proto Endo and Pantocalcic) and agrotechnology (NT or CT) in PCspace-based TS OM composition

The first two PC axes describe 51\% of the variation between soil variants, PC1 $33 \%$ and PC2 18\%. Eigenvectors of TS OM compounds were used for estimation of their influence on differences between variants (Table 5S). Axis PC1 predominantly divides the soils on the subtype, i.e. by Ca content or aridity. The shift along the PC2 axis more reflects the effect of agrotechnology. The introduction of NT shifts all soil down to the PC2 axis.

\subsubsection{Relations TS OM with the aridity of Chernozems}

In the gradient of Chernozems aridity from Protocalcic to Endo and Pantocalcic, the abundance of some pyrolisates of TS OM such as six-membered rings in with nitrogen and aromatic compounds decreases; at the same time, the contents of acyclic unsubstituted and O-substituted compounds as well as pyridine increase. Notably there is a paradoxical opposite tendency between methylpyridines (N6, see Fig. 2, Table S6) and unsubstituted pyridine (Pr). Recently, by pyrolysis of podzols at $600^{\circ} \mathrm{C}$, it was demonstrated that pyridine was associated with high solubility and degree of decomposition of OM [24]. Likewise, Schellekens et al. (2009) [25] showed that the high content of pyridine designates on more decomposed OM. Schulten et al. (1995) [26] point out a negative correlation between the total $\mathrm{N}$ concentrations in agricultural soils and the relative signal intensity of pyridine They conclude that pyridines are relevant natural constituents of soil $\mathrm{N}$ because other pyrolysis products of proteinaceous material did not show a similar correlation[26]. In addition, there is an opinion that pyridine can be considered as a 
marker of black carbon [27]. In a study, Grandy et al [28]. identified a positive correlation of pyridine with the activity of at least two enzymes and a negative correlation with the fungal:bacterial ratio.

In this way, during pyrolysis from less-decomposed Chernozems OM (Protocalcic) in our work, we released more methylpyridines, and on the contrary, pyrolysates of more transformed OM contain more unsubstituted pyridine. Thus, on the one hand, our data confirm the behaviour of pyridine according to the degree of decay of Chernozem OM, but the other hand, our date demonstrate that substituted pyridines behave differently. This was probably due to a temperature of $500^{\circ} \mathrm{C}$ at the second step of pyrolysis. A using relative low pyrolysis temperature support more molecular diversity of pyrolysates. Our preliminary experiments demonstrated that the optimal temperature for studying the $\mathrm{OM}$ of Chernozems is $500^{\circ} \mathrm{C}$ [29]. The total area of the TIC at $500^{\circ} \mathrm{C}$ does not notably differ from the TIC at higher temperatures $\left(600,700^{\circ} \mathrm{C}\right)$, while at $500^{\circ} \mathrm{C}$, much more wellresolved peaks were observed. At higher pyrolysis temperatures, pyridine derivatives are degraded to free pyridine. Therefore, it is practically impossible to reveal links between pyridine derivatives and the state of organic matter during pyrolysis above $500^{\circ} \mathrm{C}$, at least in the Chernozems, because of the abundance of pyridine in pyrolysis products at $500^{\circ} \mathrm{C}$ is higher $(6-8 \%)$ than substituted derivatives (3-5\%) see Table 3. Therefore, if the pyrolysis temperature is higher than $500^{\circ} \mathrm{C}$, all pyridine derivatives are transformed to unsubstituted pyridine and the effect of substituted pyridines can be hidden.

Like pyridine, the content of some pyrolisates such as acyclic alkanes (-enes) and oxygen-substituted alkanes (Alk and AlkO) contributes to the shift in axis PC1 to the negative area. Usually, an increase in the content of acyclic alkanes in a gradient of aridity reflects the accumulation in the $\mathrm{OM}$ of recalcitrant compounds, including plant wax components such as cutins, cutans and suberins $[19,30,31,32]$. However, in our case, a polarity column was used, and only short-chain alkanes (-enes) with 5-8 $\mathrm{C}$ were established (Table 3S). Generally, a polar column is better suited to characterise pyrolysis products such as polysaccharides, protein and lignin-derived products and alkanoic acids. However, long-chain alkanes and alkenes are not determined when using the polar column [33]. Nevertheless However, application of the polar column allowed the characterisation of short-chain products, which were probably products of the last stage of decay, as in the case of pyridine.

The PC2 divides the TS OM of Chernozems based on land management. All NT treatments shift down in comparison to CT for each Chernozems subtype. The greatest load of the PC2 eigenvectors observed one of the aromatic pyrolisates (toluene), which shifted the NT soils into a negative area. Polysaccharide fragments and N-compounds of TS OM shifted CT soils to the positive area (Table S6). Toluene may be formed upon pyrolysis of lignin or degraded lignin, the acid-insoluble residue of plant litter (Klason lignin), proteins, peptides or amino acids $[27,33,34,35,36,23]$. In support of our data, other works $[37,38]$ consider toluene as a land management-dependent marker of OM. They suggested that toluene, in contrast with benzene, comes from non-condensed aromatic rings with aliphatic chains of low OM decay.

One of the features of NT technology is a large amount of plant residuals remaining on the field. Differences in toluene content may be explained by increasing the content of lignin fragments. Supporting this is the opposite direction of the eigenvector of pyrroles to the markers of amino acid, peptides and porphirines $[26,39,40,41,42,43]$. If the main origin of toluene was from amino acids, then their eigenvectors would be co-directional. In addition to pyrroles, high positive-value eigenvectors for PC2 have other N-com- 
pounds and furan-containing polysaccharide fragments. Probably all these relations reflect microbiological activity toward the decomposition of OM, which is greater in CT than in NT.

\section{Discussion}

The ways of alteration of SOM depend on ratio availability to recalcitrant components and levels of N-compounds, which stimulate microbial activity [28] (Grandy et al., 2008). Thermal separation allows the comparison of molecular fragments of bioavailable and sustainable pools. We attempted to estimate the transformation paths from bioavailable to resistant OM depending on the subtype of Chernozems and land management. Multi correlation analyses were applied between the most significant molecular structures of TL and TS OM consistent with PCA data.

When the influence of the soil type was evaluated (differences in PC1), the general data matrix (all data) was used. Accordingly, separate matrices were used for NT and CT to estimate the SOM conversion with various agrotechnologies (differences in PC2). The significance of correlation coefficients (Table 4) was graphically tested for false correlations (Fig. S2-S4).

\subsection{OM transformation depending on the type of the Chernozems}

All polysaccharide derivatives (3-furaldehyde, furfural and 2-furancarboxaldehyde, 5methyl-) of TL OM demonstrate a negative correlation with TS acyclic aliphatic compounds (Alk) and pyridine (Pr) contents. The positive correlations of polysaccharide moieties of TL OM were with aromatic (Ar) fragments, nitrogen heterocycle compounds (both N6 and N5 except non-substituted Pr) and most polysaccharide fragments (PscF, Psc) of TS OM. The relationship of polysaccharide derivatives of TL with polysaccharide fragments of TS OM probably indicate that these TS compounds originate from TL compounds.

Aromatic compounds in TS OM partly originate from lignin [28, 44]. Because polysaccharide fragments of TL OM are an accessible substrate, their increase can increase the ability of microorganisms to decompose lignin, which also contributes to its transition to less bioavailable forms.

A joint increase abundance of polysaccharide fragments in TL and nitrogen-containing substances in TS OM indicates the same. N6 and N5 are pyrolysates of proteinaceous material [26] and transfer from bioavailable pool to TS OM through intensive microbial decay of TL OM.

The presence of an available substrate contributes to the active growth of soil biota and the accumulation of protein structures. However, after the death of microorganisms, a significant part of nitrogen appears to bind to the mineral part of the soil or be humified and pass to TS OM.

In confirmation of this assumption, $15 \mathrm{~N}$ litter-labelling experiments demonstrated that after a decade most of the label OM has moved into aggregates with density from 1.65$2.4 \mathrm{~g} / \mathrm{cm} 3$ corresponding to TS OM [45].

As already mentioned above, pyridine is associated with a high degree of decomposition of OM [24,25]. Our analysis of the relationship between free and substituted pyridines indicates various sources of these compounds. In this light, we propose pyridine as a marker of extremely decomposed OM. The next step of decomposition for these substances will be a complete decay to low molecular gases. This assumption explains the 
negative correlation between the polysaccharide fragments of TL and the pyridine of TS. In addition, such interconnectedness can also explain the negative correlation between the polysaccharide fragments of TL and the short-chain acyclic aliphatic compounds (Alk) of TS OM.

Table 4. Correlation coefficients between content for the pyrolisates of TL and TS OM

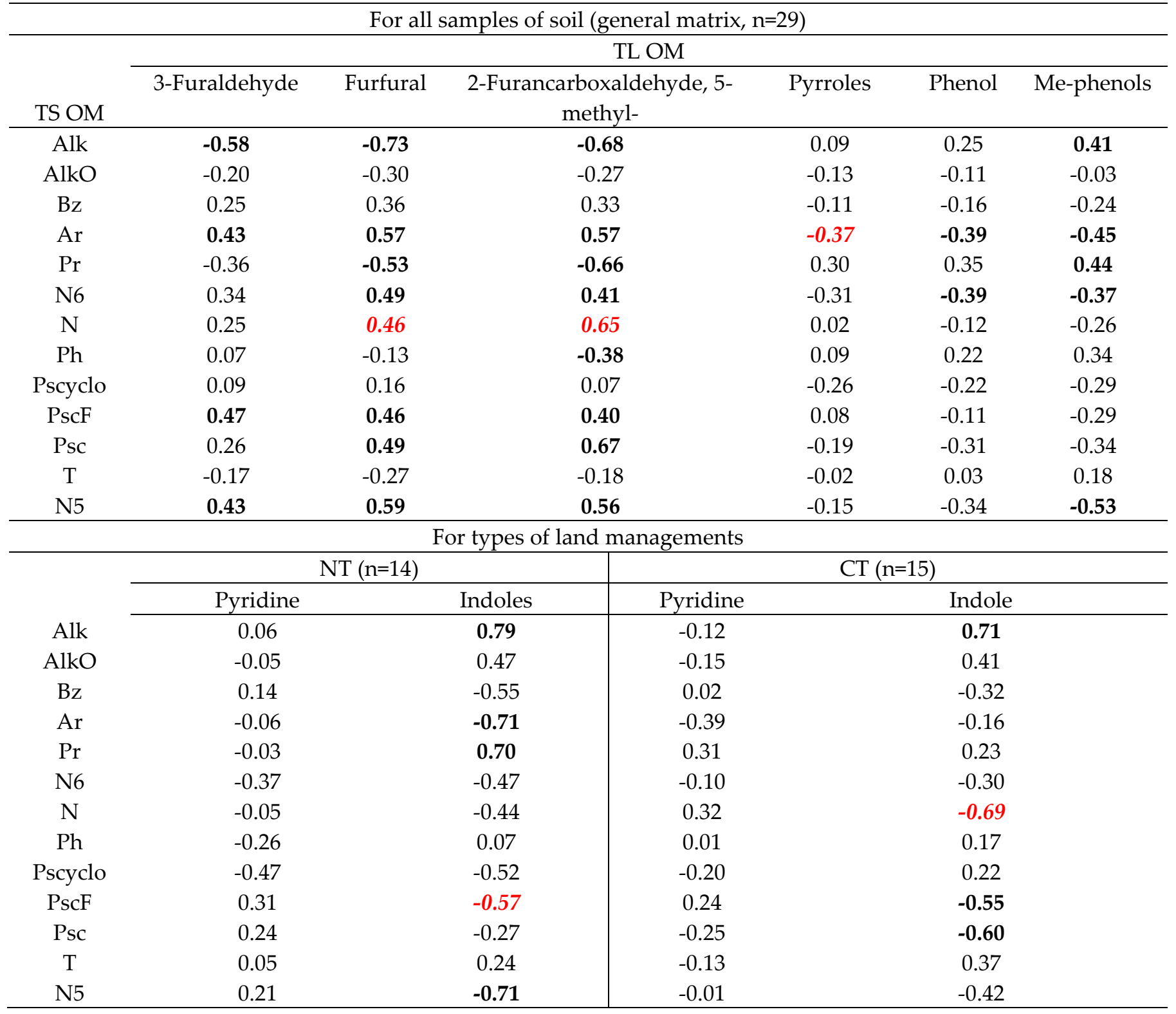

*Significant correlations are marked by bold font $(\alpha=0.05)$; false correlations are highlighted by red italic (see Fig. S2-S4)

Thus, an increase in the flow of bioavailable compounds reduces the content of deep decomposed substances due to the reduction of the share of these compounds in the soil or reducing their concentration due to the intensification of microbial decay.

The correlations for Me-phenols compounds of TL OM are opposite to the relationships of polysaccharide fragments (Table 4). The abundance of Me-phenols in the TL OM increases with an increase of the abundance of acyclic aliphatic compounds and pyridine 
and with a decrease of N5, N6 and aromatic fragments in TS OM. The Me-phenols are probably lignin fragments and are less available for decomposition than other TL compounds especially polysaccharide derivatives. It can be explained that abundance of bioavailable N-pyrolisates in first turn would be depends on more preferable substrate and may demonstrates negative relationships with less energetically profitable substrate.

4.2 OM transformation depending on the land management of the Chernozems.

The relative content of pyridine and indoles in the products of pyrolysis of TL OM made the greatest contribution to the differences between NT and CT technologies in the PCA (Fig. 1, Table S3). Therefore, to clarify the features of transformation depending on the agrotechnology, separate data subsections for NT and CT were used for multi-correlation analysis for the relative abundance of pyridine and indoles in the TL OM and pyrolysis products of the TS OM.

A relative abundance of pyridine in the products of pyrolysis of TL OM did not show relationships with substances of the TS OM in either NT or CT. Significant correlations were only found for the indole contents in the TL OM with some pyrolysates of TS OM. A positive correlation between the relative abundance of indoles in the pyrolisates of TL $\mathrm{OM}$ and a fraction of short acyclic alkanes in the pyrolisates of TS OM was observed in both the NT and CT treatments. Amino acids under pyrolysis are transformed into indoles [42]. Moreover, the indole contents were positively correlated with the major Ccycle enzymes, which use polysaccharides and lignin as substrates [28]. Because the increased content of indoles in the pyrolisates of TL OM induces biological activity in the soils, this increases the intensity of decay of OM and relative abundance of short acyclic alkanes in the pyrolisates of TS OM. No other correlation pairs coincided in the NT and CT data subsections.

In the NT treatment, the relative abundance of indoles in the composition for pyrolysates of TL OM was positively correlated with a relative abundance of pyridine in the pyrolysates of TS OM. In addition, the indole content was negatively correlated with the share of aromatic compounds and N5 in the pyrolysates of TS OM. In the case of CT, a relative abundance of indoles in the pyrolysates TL OM was negatively correlated with polysaccharide fragments Psc and PscF of TS OM (Table 4).

The NT agrotechnology, in contrast to the CT, leaves the remains of plants on the surface of the soil. However, these residuals are less available for microorganisms because plants are not ploughed into the soil as is done in CT. Pyridine, on the one hand, is the marker of most decomposed OM, and on the other hand, is a relevant natural constituent of soil $\mathrm{N}[24,25,26]$. We believe that the increasing relative abundance of indoles in the products of pyrolysis of TL OM of NT is caused by an increase in biological activity. Increasing biological activity induces partly the decomposition of old OM, which lost stability under changing conditions or in the length of time.

In the NT, there was an increased relative abundance of indoles in the composition for pyrolysates of TL OM and a decrease the relative abundance of aromatic compounds (mainly lignin derivatives) in the TS OM. At the same time in the NT TL OM, additional lignin fragments did not accumulate, at least in comparison with the CT treatment (Table 1). Thus, NT increases the biological activity of Chernozems (indoles are markers of this processes), which causes decomposition of lignin derivatives in the TS OM.

In addition, there was a negative correlation between the relative abundance of indoles in the pyrolysates of TL OM and pyrroles (N5) in the TS OM. Increasing biological activity in the NT reduces the content of amino acid products in the TS OM. Probably, using 
NT enrich with nitrogen compounds the active pool (TL OM). This should contribute to the features of the NT technology.

On the one hand, when using NT, there are more plant residues on the field compared to $\mathrm{CT}$, which helps to increase the activity of microorganisms. On the other hand, the absence of stirring of crop litter makes it difficult to transition organic matter in stable pools. However, it is worth noting all the NT treatments accumulated significantly more carbon than the CT treatments [5]. We guess that in an active pool under the NT, only the most deficient nitrogen-containing compounds are accumulated. Because of this, lack of nitrogen may occur in a stable pool (or for transformation recalcitrant $\mathrm{OM}$ ). Therefore, as the decomposition rate of OM slows down; this contributes to carbon accumulation in the NT treatments.

This assumption is confirmed by the relationship between the TL OM and TS OM of CT Chernozems. Increased biological activity (marked by indoles) in the TL OM of the CT induces a decrease in the abundance of polysaccharide fragments in the TS OM (Table 4). There are no such correlations in the NT, which indicates the lack of nitrogen for the transformation of OM in the TL OM of NT Chernozems.

\section{Conclusions}

Our study aimed to assess responses of Chernozems SOM to aridity and the introduction of the NT technology using double-shot pyrolysis GC/MS, which would provide novel insights into the alteration of $\mathrm{OM}$ in the Chernozems under climatic and agrotechnology changes.

An increase in aridity is accompanied by a decrease in the relative abundance of polysaccharide fragments and an increasing share of lignin derived and N-contented (pyrroles) components in the bioavailable pool. At the same time, the enrichment of substituted pyridines and other aromatic pyrolysates of TS OM is reduced, and the relative abundance of unsubstituted pyridines and acyclic alkanes increases in the recalcitrant pool.

The NT agrotechnology led to a compositional shift of OM of the Chernozems, with increased indole contents among pyrolysates of bioavailable OM, an increased share of toluene and decreased relative abundance of furane fragments, pyrroles and other N-compounds (except pyridine derivatives) in the recalcitrant OM. The use of NT agrotechnology increases biological activity and enriches with nitrogen compounds the bioavailable $\mathrm{OM}$; this process contributes accumulation of carbon in the recalcitrant OM.

Our results demonstrate more influence of the NT practice on recalcitrant OM in comparison to bioavailable OM. How can this be? The NT principally impacts plants and their residuals and weakly interacts with soil. In contrast, the CT action on soil is very intensive by mixing and breaking soil aggregates. Therefore, when the CT is replaced by the NT, soil aggregates begin to recover. The restoration of soil aggregates increases its ability to sequester carbon [46]. An increase of carbon sequestration means formation of soil sites capable of binding OM. We do not discuss the nature of the sites in this article; they probably appears when the properties of the soil surface change due to changing flows of OM. Unsaturated sites intensely bind fresh products of plant decay. Because the most bioavailable OM is formed during the NT practice, it rapidly passes to recalcitrant pool and differs between the TL OM of the NT and CT but is poorly expressed in comparison to TS OM.

Supplementary Materials: The following are available online at www.mdpi.com/xxx/s1, Figure S1: title, Table S1: title, Video S1: title.

Author Contributions: Conceptualization V.K, Y.F., V.B.; methodology V.K., Y.F..; formal analysis, S.Y..; investigation, N.Y., N.E.; resources, V.D., B.I.,V.L..; data curation, N.Y.; writing-original draft 
preparation, V.K., S.M.; writing - review and editing, V.K., Y.F..; visualization, V.K.; supervision, V.K..; All authors have read and agreed to the published version of the manuscript.

Funding: This work was supported by Russian Science Foundation (project \# 19-16-00053).

Conflicts of Interest: The authors declare that they have no known competing financial interests or personal relationships that could have appeared to influence the work reported in this paper.

\section{References}

1. Jobaggy, E.G., Jackson, R.B., 2000. The vertical distribution of soil organic carbon and its relation to climate and vegetation. Ecol. Appl. 10, 423-436. https://doi.org/10.2307/2641104

2. Lal, R., 2004. Soil carbon sequestration impacts on global climate change and food security. Science 304, $1623-1627$. https://doi.org/10.1126/science.1097396

3. Powlson, D.S., Stirling, C.M., Jat, M.L., Gerard, B.G., Palm, C.A., Sanchez, P.A., Cassman, K.G., 2014. Limited potential of no-till agriculture for climate change mitigation. Nat. Clim. Change. 4, 678-683. https://doi.org/10.1038/nclimate2292

4. Roper, M.M., Kerr, R., Ward, P.R., Micin, S.F., Krishnamurthy, P., 2021. Changes in soil properties and crop performance on stubble-burned and cultivated water-repellent soils can take many years following reversion to no-till and stubble retention. Geoderma 402, 115361. https://doi.org/10.1016/j.geoderma.2021.115361

5. Kholodov, V.A., Belobrov, V.P., Yaroslavtseva, N.V., Yashin, M.A., Yudin, S.A., Ermolaev, N.R., Dridiger, V.K., Ilyin, B.S., Lazarev, V.I., 2021. Influence of no-till system on the distribution of organic carbon and nitrogen by aggregate size fractions in Protocalcic, Endocalcic, and Pantocalcic Chernozems. Eurasian Soil Sci. 54, 285-290. https://doi.org/10.1134/S1064229321020071

6. Plante, A.F., Fernández, J.M., Leifeld, J., 2009. Application of thermal analysis techniques in soil science. Geoderma 153, 110. https://doi.org/10.1016/J.GEODERMA.2009.08.016

7. Gregorich, E. G., Gillespie, A. W., Beare, M. H., Curtin, D., Sanei, H., \& Yanni, S. F., 2015. Evaluating bio-degradability of soil organic matter by its thermal stability and chemical composition. Soil Biol. Biochem. 91, 182191.https://doi.org/10.1016/j.soilbio.2015.08.032

8. Kalbitz, K., Schwesig, D., Schmerwitz, J., Kaiser, K., Haumaier, L., Glaser, B., Ellerbrock, R., Leinweber, P., 2003. Changes in properties of soil-derived dissolved organic matter induced by biodegradation. Soil Biol. Biochem. 35, 1129-1142. https://doi.org/10.1016/S0038-0717(03)00165-2

9. Thiele-Bruhn, S., Leinweber, P., Eckhardt, K.U., Siem, H.K., Blume, H.P., 2014. Chernozem properties of Black Soils in the Baltic region of Germany as revealed by mass-spectrometric fingerprinting of organic matter. Geoderma 213, 144-154. https://doi.org/10.1016/j.geoderma.2013.07.036

10. Dorodnikov, M., Fangmeier, A., Kuzyakov, Y., 2007. Thermal stability of soil organic matter pools and their $\delta 13 C$ values after C3-C4 vegetation change. Soil Biol. Biochem. 39, 1173-1180. https://doi.org/10.1016/j.soilbio.2006.12.025

11. Derenne, S., Quéné, K., 2015. Analytical pyrolysis as a tool to probe soil organic matter. J. Anal. Appl. Pyrolysis 111, 108120. https://doi.org/10.1016/j.jaap.2014.12.001

12. Quénéa, K., Derenne, S., González-Vila, F.J., González-Pérez, J.A., Mariotti, A., Largeau, C., 2006. Double-shot pyrolysis of the non-hydrolysable organic fraction isolated from a sandy forest soil (Landes de Gascogne, South-West France): Comparison with classical Curie point pyrolysis. J. Anal. Appl. Pyrolysis 76, 271-279. https://doi.org/10.1016/j.jaap.2005.12.007

13. Gillespie, A.W., Sanei, H., Diochon, A., Ellert, B.H., Regier, T.Z., Chevrier, D., Dynes, J.J., Tarnocai, C., Gregorich, E.G., 2014. Perennially and annually frozen soil carbon differ in their susceptibility to decomposition: Analysis of subarctic earth hummocks by bioassay, XANES and pyrolysis. Soil Biol. Biochem. 68, 106-116. https://doi.org/10.1016/j.soilbio.2013.09.021

14. Tamimi, N., Schaumann, G.E., Diehl, D., 2017. The fate of organic matter brought into soil by olive mill wastewater application at different seasons. J. Soils Sediments 17, 901-916. https://doi.org/10.1007/s11368-016-1584-1

15. Kholodov, V.A., Farkhodov, Y.R., Yaroslavtseva, N. V., Aydiev, A.Y., Lazarev, V.I., Ilyin, B.S., Ivanov, A.L., Kulikova, N.A., 2020. Thermolabile and thermostable organic matter of Chernozems under different land uses. Eurasian Soil Sci. 53, 10661078. https://doi.org/10.1134/S1064229320080086

16. IUSS Working Group WRB, World Reference Base for Soil Resources, 2014. International Soil Classification System for Naming Soils and Creating Legends for Soil Maps, World Soil Resources Report No. 106 (US Food and Agriculture Organization, Rome, 2014). Update 2015.

17. Brock, O., Kalbitz, K., Absalah, S., Jansen, B., 2020. Effects of development stage on organic matter transformation in Podzols. Geoderma 378, 114625. https://doi.org/10.1016/j.geoderma.2020.114625

18. De la Rosa, J.M., Faria, S.R., Varela, M.E., Knicker, H., González-Vila, F.J., González-Pérez, J.A., Keizer, J., 2012. Characterization of wildfire effects on soil organic matter using analytical pyrolysis. Geoderma 191, 24-30. https://doi.org/10.1016/j.geoderma.2012.01.032

19. Hasegawa, S., Marshall, J., Sparrman, T., Näsholm, T., 2021. Decadal nitrogen addition alters chemical composition of soil organic matter in a boreal forest. Geoderma 386. 114906. https://doi.org/10.1016/j.geoderma.2020.114906 
20. Aitchison, J., 1986. The statistical analysis of compositional data. Journal of the Royal Statistical Society. Series B (Methodological) 44, 139-177. http://links.jstor.org/sici?sici=0035-9246\%281982\%2944\%3A2\%3C139\%3ATSAOCD\%3E2.0.CO\%3B2-9 Journal

21. Aitchison, J., 2008. The single principle of compositional data analysis, continuing fallacies, confusions and misunderstandings and some suggested remedies. CoDaWork 2008, 1-28.

22. Kholodov, V.A., Yaroslavtseva, N.V., Farkhodov, Y.R., Belobrov, V.P., Yudin, S.A., Aydiev, A.Y., Lazarev, V.I., Frid, A.S., 2019. Changes in the ratio of aggregate fractions in humus horizons of Chernozems in response to the type of their use. Eurasian Soil Sci. 52, 162-170. https://doi.org/10.1134/S1064229319020066

23. Vancampenhout, K., Wouters, K., De Vos, B., Buurman, P., Swennen, R., Deckers, J., 2009. Differences in chemical composition of soil organic matter in natural ecosystems from different climatic regions - A pyrolysis-GC/MS study. Soil Biol. Biochem. 41, 568-579. https://doi.org/10.1016/j.soilbio.2008.12.023

24. Lopes-Mazzetto, J.M., Schellekens, J., Vidal-Torrado, P., Buurman, P., 2018. Impact of drainage and soil hydrology on sources and degradation of organic matter in tropical coastal podzols. Geoderma 330, 79-90. https://doi.org/10.1016/j.geoderma.2018.05.015

25. Schellekens, J., Buurman, P., Pontevedra-Pombal, X., 2009. Selecting parameters for the environmental interpretation of peat molecular chemistry - A pyrolysis-GC/MS study. Org. Geochem. 40, 678-691. https://doi.org/10.1016/j.orggeochem.2009.03.006

26. Schulten, H.R., Sorge, C., Schnitzer, M., 1995. Structural studies on soil nitrogen by Curie-point pyrolysis-gas chromatography/mass spectrometry with nitrogen-selective detection. Biol. Fertil. Soils 20, 174-184. https://doi.org/10.1007/BF00336555

27. Campo, J., Nierop, K.G.J., Cammeraat, E., Andreu, V., Rubio, J.L., 2011. Application of pyrolysis-gas chromatography/mass spectrometry to study changes in the organic matter of macro- and microaggregates of a Mediterranean soil upon heating. Journal of Chromatography A 1218, 4817-4827. https://doi.org/10.1016/j.chroma.2011.03.038

28. Grandy, A.S., Strickland, M.S., Lauber, C.L., Bradford, M.A., Fierer, N., 2009. The influence of microbial communities, management, and soil texture on soil organic matter chemistry. Geoderma 150, 278-286. https://doi.org/10.1016/j.geoderma.2009.02.007

29. Kholodov, V.A., Farkhodov, Yu.R., Zherebker, A., Yaroslavtseva, N.V., 2018. The assessment of analytical double-shot pyrolysis with gas chromatograph-mass spectrometry application opportunity for the humic matter investi-gation in situ. Dokuchaev Soil Bulletin 94: 3-18. doi:10.19047/0136-1694-2018-94-3-18

30. Baldock, J.A., Oades, J.M., Nelson, P.N., Skene, T.M., Golchin, A., Clarke, P., 1997. Assessing the extent of decomposition of natural organic materials using solid-state 13C NMR spectroscopy. Soil Res. 35, 1061-1084. https://doi.org/10.1071/S97004

31. Hayes, M.H.B. 2009. Evolution of concepts of environmental natural nonliving organic matter. Biophysico-chemical processes involving environmental organic matter in natural nonliving systems. Ed. Senesi, N., Xing, B., Huang, P.M., John Wiley \& Sons, Inc., Hoboken, New Jersey. 1-40. https://doi.org/10.1002/9780470494950.ch1

32. Shen, Q., Suarez-Abelenda, M., Camps-Arbestain, M., Calvelo Pereira, R., McNally, S.R., Kelliher, F.M., 2018. An investigation of organic matter quality and quantity in acid soils as influenced by soil type and land use. Geoderma 328, 44-55. https://doi.org/10.1016/j.geoderma.2018.05.006

33. Dignac, M.F., Houot, S., Derenne, S., 2006. How the polarity of the separation column may influence the characterization of compost organic matter by pyrolysis-GC/MS. J. Anal. Appl. Pyrolysis. 75, 128-139. https://doi.org/10.1016/j.jaap.2005.05.001

34. Cotrimet Da Cunha, L., Serve, L., Gadel, F., Blazi, J.L., 2000. Characterisation of riverine particulate organic matter by pyrolysis-gas chromatography-mass spectrometry. Sci. Total Environ. 256, 191-204. https://doi.org/10.1016/S00489697(00)00492-7

35. El Fels, L., Lemee, L., Ambles, A., Hafidi, M., 2014. Identification and biotransformation of lignin compounds during cocomposting of sewage sludge-palm tree waste using pyrolysis-GC/MS. Int. Biodeterior. Biodegrad. 92, $26-35$. https://doi.org/10.1016/j.ibiod.2014.04.001

36. Kebelmann, K., Hornung, A., Karsten, U., Griffiths, G., 2013. Intermediate pyrolysis and product identification by TGA and Py-GC/MS of green microalgae and their extracted protein and lipid components. Biomass and Bioenergy 49, 38-48. https://doi.org/10.1016/j.biombioe.2012.12.006

37. Aranda, V., Ayora-Cañada, M.J., Domínguez-Vidal, A., Martín-García, J.M., Calero, J., Delgado, R., Verdejo, T., GonzálezVila, F.J., 2011. Effect of soil type and management (organic vs. conventional) on soil organic matter quality in olive groves in a semi-arid environment in Sierra Mágina Natural Park (S Spain). Geoderma 164, 54-63. https://doi.org/10.1016/j.geoderma.2011.05.010

38. Ceccanti, B., Masciandaro, G., Macci, C., 2007. Pyrolysis-gas chromatography to evaluate the organic matter quality of a mulched soil. Soil Till Res. 97, 71-78. doi:10.1016/j.still.2007.08.011

39. González-Pérez, M., Buurman, P., Vidal-Torrado, P. and Martin-Neto, L. 2012. Pyrolysis-gas chromatography/mass spectrometry characterization of humic acids in coastal spodosols from southeastern Brazil. Soil Sci Soc Am J.76, 961-971. https://doi.org/10.2136/sssaj2011.0178

40. Emran, M., Doni, S., Macci, C., Masciandaro, G., Rashad, M., Gispert, M., 2020. Susceptible soil organic matter, SOM, fractions to agricultural management practices in salt-affected soils. Geoderma 366, 114257. https://doi.org/10.1016/j.geoderma.2020.114257 
41. Leinweber, P., Jandl, G., Eckhardt, K.U., Kruse, J., Walley, F.L., Khan, M.J., Blyth, R.I.R., Regier, T., 2010. Nitrogen speciation in fine and coarse clay fractions of a Cryoboroll - new evidence from pyrolysis-mass spectrometry and nitrogen K-edge XANES. Can J Soil Sci. 90, 309-318. https://doi.org/10.4141/CJSS09063

42. Schulten, H.R., Schnitzer, M., 1997. The chemistry of soil organic nitrogen: A review. Biol. Fertil. Soils $26,1-15$. https://doi.org/10.1007/s003740050335

43. Zhang, Z., Wang, J.J., Lyu, X., Jiang, M., Bhadha, J., Wright, A., 2019. Impacts of land use change on soil organic matter chemistry in the Everglades, Florida - a characterization with pyrolysis-gas chromatography-mass spectrometry. Geoderma 338, 393-400. https://doi.org/10.1016/j.geoderma.2018.12.041

44. Miralles, I., Piedra-Buena, A., Almendros, G., Gonzalez-Vila, F.J., Gonzalez-Perez, J.A., 2015. Pyrolytic appraisal of the lignin signature in soil humic acids: Assessment of its usefulness as carbon sequestration marker. J. Anal. Appl. Pyrolysis. 113, 107-115. https://doi.org/10.1016/j.jaap.2014.11.010

45. Hatton, P.J., Kleber, M., Zeller, B., Moni, C., Plante, A.F., Townsend, K., Gelhaye, L., Lajtha, K., Derrien, D., 2012. Transfer of litter-derived $\mathrm{N}$ to soil mineral-organic associations: Evidence from decadal $15 \mathrm{~N}$ tracer experiments. Org. Geochem. 42 , 1489-1501. https://doi.org/10.1016/j.orggeochem.2011.05.002

46. Paustian, K., Six, J., Elliott, E., 1999. Aggregate and soil organic matter dynamics under conventional and no-tillage systems. Soil Sci. Soc. Am. J. 63, 1350-1358. 